\title{
A expansão dos cursos de graduação em Enfermagem: cenário, interesses e desafios do ensino a distância
}

\author{
Expansion of undergraduate Nursing courses: distance \\ education scenario, interests, and challenges \\ Expansión de cursos de grado en Enfermería: escenario, \\ intereses y desafíos en enseñanza a distancia
}

Como citar este artigo:

Saraiva AKM, Macedo CM, Leonello VM, Oliveira MAC. Expansion of undergraduate Nursing courses: distance education scenario, interests, and challenges. Rev Esc Enferm USP. 2021;55:e03784. https://doi.org/10.1590/S1980-220X2020009903784

\section{Ana Karinne de Moura Saraiva ${ }^{1}$ \\ Cibele Monteiro Macedo² \\ Valéria Marli Leonello ${ }^{2}$ \\ Maria Amélia de Campos Oliveira²}

${ }^{1}$ Universidade do Estado do Rio Grande do Norte, Faculdade de Enfermagem, Mossoró, RN, Brasil.

${ }^{2}$ Universidade de São Paulo, Escola de Enfermagem, São Paulo, SP, Brasil.

\begin{abstract}
Objective: To analyze the expansion of undergraduate Nursing courses in Brazil, especially those in the distance education modality. Methods: Exploratory, descriptive, analytical, and documentary study that used the Statistical Overview of Higher Education - Undergraduate Courses, of the Brazilian National Institute for Educational Studies and Research "Anísio Teixeira", which is part of the Ministry of Education and Culture, as a source of secondary data for the period between 2009 and 2018. Results: There was a growth in the number of undergraduate Nursing courses and new seats in the distance education modality. However, only $8.89 \%$ of these seats were occupied and $3.39 \%$ of the enrolled students completed the course, which accounted for $0.30 \%$ of the new seats. Conclusion: The expansion of undergraduate Nursing courses is aligned with the general trends in higher education. This scenario exposes the interests of capital in education, which emphasizes the need for collective development of strategies to guarantee the right to education that is public, free and has social quality.
\end{abstract}

\section{DESCRIPTORS}

Education, Higher; Education, Distance; Nursing. 


\section{INTRODUÇÃO}

O capitalismo neoliberal contemporâneo, sob a dominância financeira, tem produzido um novo padrão de acumulação mundial que permite a produção e a circulação de capitais numa escala mundializada ${ }^{(1)}$, concentrando riqueza com desigualdade social( ${ }^{(2)}$, ao mesmo tempo em que intensifica os mecanismos de mercantilização e privatização ${ }^{(3)}$. Desdobra-se em um ideário assentado no individualismo e no empresariamento de si, o que tem estimulado a concorrência, a competição, a subordinação e a conversão dos direitos sociais em serviços a serem consumidos no mercado ${ }^{(4)}$.

Esse modelo tem produzido a exclusão crescente de grandes contingentes populacionais, sujeitos a fome, miséria, violência, perda de direitos sociais e sentimentos de instabilidade, perigo, isolamento, desproteção e desamparo ${ }^{(1)}$. Aumenta a desigualdade social, a exploração, o desemprego e o subemprego, a precarização de relações e condições de trabalho, o arrocho salarial e os valores liberais conservadores ${ }^{(5)}$.

No campo educacional, a adoção da pauta do capitalismo mundializado estabelece-se por meio de uma série de medidas, enfeixadas ou não, sob a denominação de reformas que, além das especificidades locais, evidenciam uma profunda redefinição do papel do Estado em sua relação com a Educação. Assiste-se à retração financeira do Estado na prestação de serviços sociais e à subsequente privatização ou, ao menos, tentativa de privatização desses serviços ${ }^{(6)}$.

Nessa correlação de forças, há diminuição das atribuições estatais de cunho social universalista e ampliação do espaço e do poder dos interesses privados ${ }^{(6)}$. Assim, as políticas educacionais têm reduzido a formação aos interesses do mercado, traduzidos em um perfil produtivo, flexível, adaptável, capaz de suportar e aceitar a intensificação e a precarização do trabalho ${ }^{(7)}$.

Esse contexto desdobra-se na massificação da formação em Instituições de Ensino Superior (IES) privadas, cujos egressos destinam-se a empregos precarizados, com baixo conhecimento técnico e sujeitos a maior exploração. Contribui ademais para a produção e a divulgação mercantilizada de conhecimentos que, sob o nome de inovação, aprofunda a privatização da ciência por meio de parecerias público-privadas ${ }^{(7)}$.

As tendências recentes da Educação Superior no Brasil expressam-se em aumento significativo de IES privadas/mercantis; adoção de políticas governamentais que incentivam o crescimento de vagas, matrículas e cursos em Instituições Federais de Ensino Superior (IFES); forte diferenciação de cursos, instituições e modalidades de ensino, com destaque para o Ensino a Distância (EAD), e expansão da pós-graduação, com ênfase no empresariamento do conhecimento ${ }^{(8)}$.

Embora a definição do EAD seja bastante polissêmica, em geral, é conceituado como como uma modalidade de ensino em que professor e aluno estão geograficamente em lugares diferentes. É anterior ao advento da Internet, com início no século XVIII, por meio de cursos realizados pelo correio.

Já o e-learning, também definido de diferentes formas na literatura, ocorre quando há o uso de tecnologias da Internet, para promover o aprendizado do estudante. Pode ser síncrono, quando realizado ao mesmo tempo, ou assíncrono, quando as atividades são gravadas e veiculadas aos aprendizes que podem acessá-las a qualquer tempo. Existem outros termos relacionados à composição articulada entre o ensino presencial e a distância, considerado híbrido (blended learning ou b-learning), bem como termos relacionados à especificidade dos dispositivos remotos utilizados para o aprendizado, (mobile learning ou $m$-learning) ${ }^{(9)}$.

Em que pesem as diferenças terminológicas, a legislação brasileira define EAD como uma modalidade educacional mediada pelo uso de meios e tecnologias da informação e comunicação, destacando a necessidade de pessoal qualificado e políticas de acesso, acompanhamento e avaliação compatíveis. $\mathrm{O}$ recente decreto do Ministério da Educação e Cultura (MEC) $n^{\circ}$ 9.057 de 2017 também refere que a modalidade é relacionada a atividades educativas entre professores e estudantes em "lugares e tempos diversos", o que permite a interpretação de que as atividades podem ser síncronas e assíncronas ${ }^{(10)}$.

O EAD está previsto desde a Lei de Diretrizes e Bases (LDB) da educação de $1996^{(11)}$. Porém, foi por meio do decreto supramencionado que houve ampliação, diversificação e flexibilização dessa modalidade de ensino no que diz respeito a criação, funcionamento e avaliação dos cursos. Dentre as mudanças, destaca-se a criação de polos presenciais pelas próprias instituições, sem autorização prévia do MEC, bem como a oferta de cursos na modalidade EAD, sem exigir o credenciamento prévio para a oferta presencial ${ }^{(12)}$. Em outras palavras, a nova legislação garantiu mais autonomia e flexibilidade para a abertura de polos, resultando em incremento de 51\% do número de cursos de EAD entre 2017 e 2018, especialmente na rede privada de ensino superior. Em 2018, mais de 80\% dos alunos de EAD no país estavam concentrados em 20 IES e cinco delas, de caráter privado, detinham as matrículas de mais da metade desses alunos.

A ampliação e a intensificação do $\mathrm{EAD}$ no Brasil também foram favorecidas pela Portaria n ${ }^{\circ} 2.117$ de 6 dezembro de 2019, que autoriza que até $40 \%$ da carga horária total de cursos de graduação presenciais nas IFES seja ofertada nessa modalidade.

É nesse contexto que se insere o processo de expansão da formação em Enfermagem, produto de uma multiplicidade de processos sociais e históricos que resulta da prática da categoria e dos contextos sociais em que essa prática se desenvolve, modificando-se dinamicamente. Sob essa ótica, a educação em Enfermagem não é algo idealizado, abstrato, mas parte e produto do processo da própria sociedade ${ }^{(13-14)}$.

A expansão da educação superior em Enfermagem tem ocorrido por meio da abertura indiscriminada de novos cursos, ausência de articulação entre a abertura desses cursos e as necessidades e as demandas específicas de cada região, acentuando a desigualdade geográfica, expressa em desequilíbrio regional e intrarregional, privatização, proliferação descontrolada de cursos e instituições cada vez mais distantes da ideia de universidade e de padrões mínimos de qualidade ${ }^{(15)}$. Como parte desse processo, ampliaram-se os cursos e as vagas na modalidade EAD, com o argumento de facilitar o acesso e, por conseguinte, garantir a democratização do ensino superior.

A literatura sobre a expansão de cursos de graduação em Enfermagem ainda não conseguiu avançar com objetividade e criticidade sobre esse fenômeno, havendo uma lacuna empírica em torno de suas implicações, para o processo de formação em Enfermagem $^{(15)}$, em especial sua articulação ao processo mais 
geral da expansão e mercadorização da educação superior no Brasil. Essa escassez teórico-metodológica amplia-se no que se refere ao EAD na graduação em Enfermagem.

Assim, o presente artigo tem como objetivo analisar a expansão dos cursos de graduação em Enfermagem no Brasil, em particular na modalidade de EAD.

\section{MÉTODO}

\section{TIPO DE ESTUDO}

Estudo exploratório, descritivo, analítico e documental que buscou analisar a expansão do ensino de graduação em Enfermagem como um fenômeno social, a partir dos limites e das possibilidades do contexto histórico-social em que se insere ${ }^{(14)}$.

\section{FonTE DE DADOS E CRITÉRIOS DE SELEÇÃo}

Utilizaram-se dados secundários provenientes das Sinopses Estatísticas da Educação Superior - Graduação, do Instituto Nacional de Estudos e Pesquisas Educacionais Anísio Teixeira do Ministério da Educação (Inep/MEC). Essas Sinopses consolidam os dados recolhidos pelo Censo da Educação Superior (Censup) nas IES do país e constituem a principal fonte de dados oficiais sobre Educação Superior do Brasil. Encontram-se disponíveis publicamente para download e reúnem um conjunto de dados sobre as IES, os cursos ofertados, os docentes, os funcionários técnico-administrativos, entre outros, em tabelas no formato Excel ${ }^{\circledR}$.

No portal eletrônico Inep/MEC há Sinopses Estatísticas da Educação Superior desde 1995, porém o recorte temporal para este estudo foi de nove anos, entre 2009 e 2018, período compreendido entre a oferta do primeiro curso de graduação a distância em Enfermagem registrado e a última sinopse disponível em setembro de 2019, mês da recolha dos dados.

\section{Coleta de dados}

Considerando o objetivo proposto pelo estudo, foram extraídos dados relativos a: a) cursos de graduação presenciais e a distância, por organização acadêmica e categoria administrativa das IES; b) vagas oferecidas, candidatos inscritos e ingressos por processos seletivos nos cursos de graduação a distância, por organização acadêmica; c) matrículas dos cursos de graduação a distância por organização acadêmica e categoria administrativa; d) concluintes dos cursos de graduação a distância por organização acadêmica e categoria administrativa das IES.

A extração dos dados foi realizada separadamente por dois pesquisadores, e posteriormente os dados foram confrontados para garantir sua fidedignidade. Em seguida, foram organizados e sistematizados em um banco, com o apoio da ferramenta Microsoft Excel $^{\circledR}$ (2016), seguindo o formato do banco de dados das Sinopses estatísticas.

\section{ANÁLISE E TRATAMENTO DOS DADOS}

A estatística descritiva foi utilizada para identificar os dados referentes à expansão dos cursos de graduação em Enfermagem nas modalidades presencial e a distância, ao longo do período analisado. De posse da totalidade das informações, realizou-se um movimento descritivo e analítico, articulando os resultados ao contexto histórico e à expansão da educação superior no Brasil, reconhecendo o movimento dialético desse processo.

\section{AsPeCtOS ÉTICOS}

Ressalta-se ainda que, por se tratar de fontes documentais disponíveis para consulta pública, há dispensa de apreciação do Comitê de Ética, conforme as Resoluções Éticas $n^{\circ} 466 / 2012$ e n ${ }^{\circ} 510 / 2016$.

\section{RESULTADOS}

No que se refere à modalidade presencial, existiam 39 cursos de graduação em Enfermagem em 1964, que passaram para 106 em 1991, uma expansão de 171,0\%. Em 2004, esse número saltou para 415, o que representa um incremento de 291,5\%. A partir da Lei de Diretrizes e Bases da Educação de 1996, a expansão foi ainda mais acentuada. De 1991 até 1996, foram criados apenas cinco cursos, ou seja, um crescimento de apenas $4,7 \%$, enquanto que, de 1991 a 2010, o aumento foi de 645,3\%(16).

De acordo com o Censo da Educação Superior, em 2018, havia 1.041 cursos de graduação em Enfermagem, o que significa uma ampliação de aproximadamente 8,8 vezes desde 1991. Ao analisar o período entre 2009 e 2018, identifica-se que a expansão dos cursos presenciais de graduação em Enfermagem $(38,4 \%)$ foi relativamente superior ao movimento geral dos cursos superiores no Brasil (25,0\%) (Figura 1).

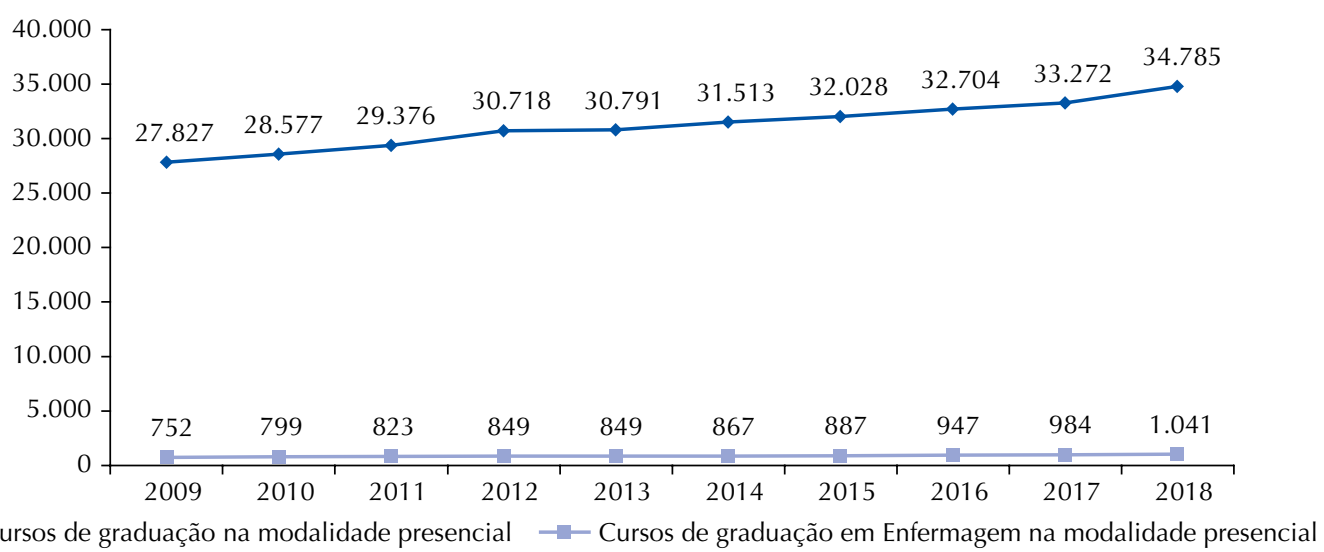

Fonte: INEP/MEC.

Figura 1 - Expansão do número de cursos de graduação e de Enfermagem na modalidade presencial, entre os anos de 2009 e 2018, no Brasil. 
No que se refere a todos os cursos de EAD no Brasil, entre os anos de 2009 e 2018, houve um aumento de aproximadamente 2,76 vezes. No mesmo período, o incremento do número de cursos de $\mathrm{EAD}$ no ensino superior de Enfermagem foi de 2,50 vezes (Figura 2). Entre os anos
2017 e 2018, período de publicação da nova regulamentação para o EAD no Brasil, houve aumento significativo na oferta de cursos de graduação em Enfermagem (250,0\%). Nesse mesmo período, a expansão dos cursos de EAD foi de aproximadamente $51,0 \%$.

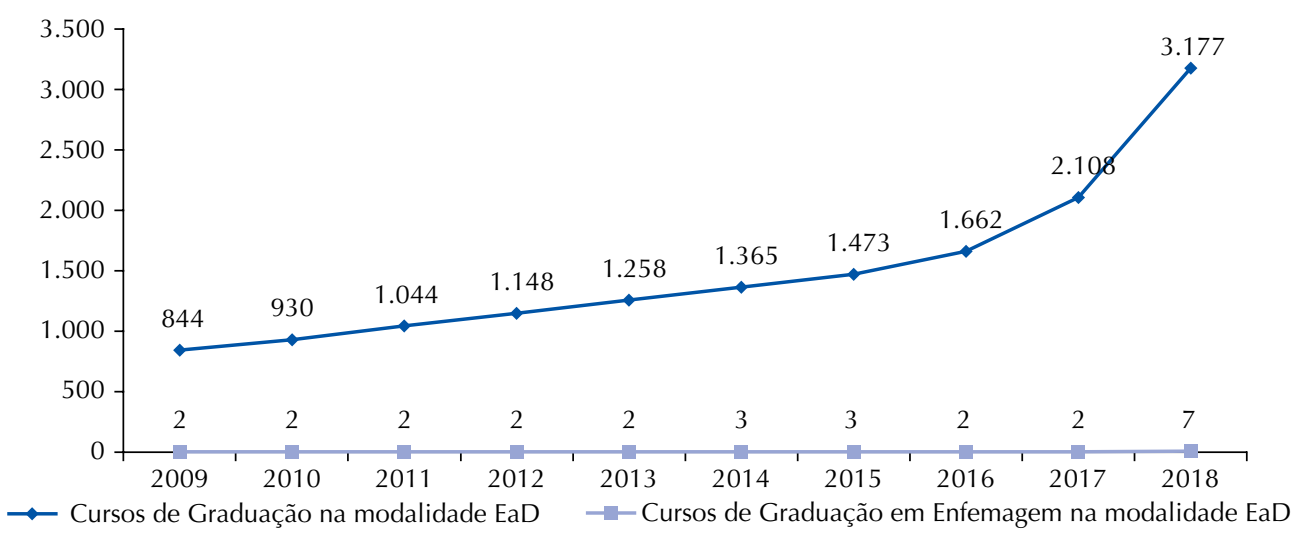

Fonte: INEP/MEC

Figura 2 - Expansão do número de cursos de Graduação no Brasil e dos cursos de Enfermagem na modalidade a distância, entre os anos de 2009 e 2018.

Em relação aos cursos de Enfermagem, entre 2009 e 2018, houve expansão acentuada da modalidade a distância $(250,0 \%)$, em comparação à presencial, em que o aumento correspondeu a $38,43 \%$, conforme se pode visualizar na Figura 3. Contudo, é importante ponderar que, em números absolutos, os cursos presenciais continuam expressivamente superiores aos EAD. Observa-se que o crescimento é mais acelerado a partir de 2017. Nota-se estabilidade no número de cursos de EAD até 2017, com cerca de dois cursos em todo o país, e aumento expressivo em 2018, com ampliação para sete cursos nessa modalidade.
Em que pese o aumento significativo no número de cursos de graduação no EAD entre 2017 e 2018, os dados evidenciam que a expansão dessa modalidade ocorreu de forma distinta da presencial, uma vez que dependeu quase exclusivamente do aumento do número de vagas, e não da criação de novos cursos. A ampliação significativa da oferta de novas vagas em cursos EAD em Enfermagem correspondeu a um aumento de 32,2 vezes entre os anos de 2009 e 2018. Em 2016, por exemplo, dois cursos no Brasil ofertavam 72.509 vagas nessa modalidade de ensino (Figura 3).

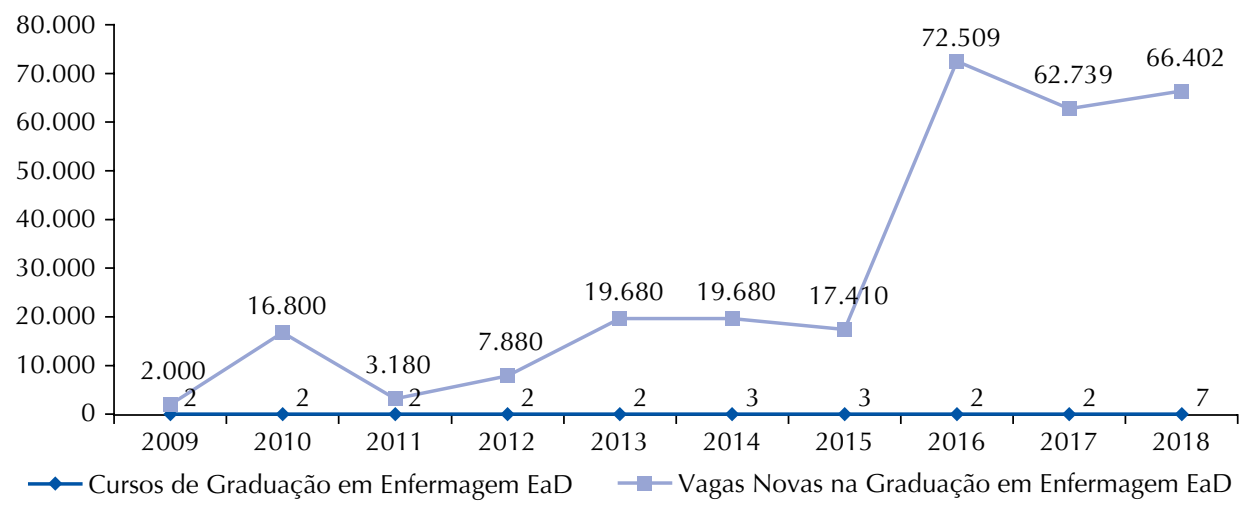

Fonte: INEP/MEC

Figura 3 - Número de cursos e novas vagas de graduação em Enfermagem EAD no Brasil, entre os anos de 2009 e 2018.

Em 2018, sete cursos ofereciam um total de 66.402 vagas novas (Figura 3). É interessante observar que o aumento de vagas foi anterior ao aumento do número de cursos nessa modalidade e que a concentração de novas vagas por curso é alta, cerca de 9.000 para cada um dos sete cursos de EAD em Enfermagem no País.

No que se refere à organização acadêmica e administrativa dos cursos de graduação em Enfermagem na modalidade presencial, a expansão ocorreu prioritariamente em centros universitários e faculdades isoladas de natureza privada. $\mathrm{Na}$ modalidade $\mathrm{EAD}$, todos os cursos desde 2009 e, por conseguinte, as vagas ofertadas, as matrículas realizadas e os alunos concluintes vinculam-se a universidades ou centros universitários privados. Desse modo, os 763 enfermeiros formados na modalidade EAD nesse período (2009-2018), no Brasil, são provenientes de IES privadas, como pode ser observado nas Tabelas 1 e 2 . 
Tabela 1 - Número de cursos de graduação presenciais de Enfermagem no Brasil, entre os anos de 2009 e 2018, por organização acadêmica - São Paulo, 2019.

\begin{tabular}{|c|c|c|c|c|c|c|c|c|c|c|c|}
\hline & & & & & & Ano & & & & & \\
\hline & & 2009 & 2010 & 2011 & 2012 & 2013 & 2014 & 2015 & 2016 & 2017 & 2018 \\
\hline \multirow{3}{*}{ Universidades } & Total & 330 & 330 & 321 & 328 & 320 & 321 & 319 & 320 & 319 & 317 \\
\hline & Pública & 134 & 143 & 141 & 152 & 149 & 148 & 144 & 143 & 140 & 138 \\
\hline & Privada & 196 & 187 & 180 & 176 & 171 & 173 & 175 & 177 & 179 & 179 \\
\hline \multirow{3}{*}{$\begin{array}{l}\text { Centros } \\
\text { Universitários }\end{array}$} & Total & 100 & 100 & 104 & 112 & 114 & 121 & 129 & 149 & 167 & 205 \\
\hline & Pública & 1 & 1 & 1 & 3 & 3 & 3 & 2 & 3 & 2 & 4 \\
\hline & Privada & 718 & 99 & 103 & 109 & 111 & 118 & 127 & 146 & 165 & 201 \\
\hline \multirow{3}{*}{ Faculdades } & Total & 322 & 368 & 396 & 407 & 413 & 423 & 437 & 476 & 496 & 517 \\
\hline & Pública & 13 & 16 & 16 & 17 & 15 & 13 & 13 & 13 & 13 & 10 \\
\hline & Privada & 309 & 352 & 380 & 390 & 398 & 410 & 424 & 463 & 483 & 507 \\
\hline \multirow{3}{*}{ IFE e Cefet } & Total & $\cdot$ & 1 & 2 & 2 & 2 & 2 & 2 & 2 & 2 & 2 \\
\hline & Pública & . & 1 & 2 & 2 & 2 & 2 & 2 & 2 & 2 & 2 \\
\hline & Privada & & . & - & - & . & . & . & . & - & - \\
\hline \multirow{3}{*}{ Total } & Total & 752 & 799 & 823 & 849 & 849 & 867 & 887 & 947 & 984 & 1.041 \\
\hline & Pública & 148 & 161 & 160 & 174 & 169 & 166 & 161 & 161 & 157 & 154 \\
\hline & Privada & 604 & 638 & 663 & 675 & 680 & 701 & 726 & 786 & 827 & 887 \\
\hline
\end{tabular}

Fonte: INEP/MEC.

Tabela 2 - Número de matrículas em cursos de graduação a distância de Enfermagem no Brasil, entre os anos de 2009 e 2018, por organização acadêmica - São Paulo, 2019.

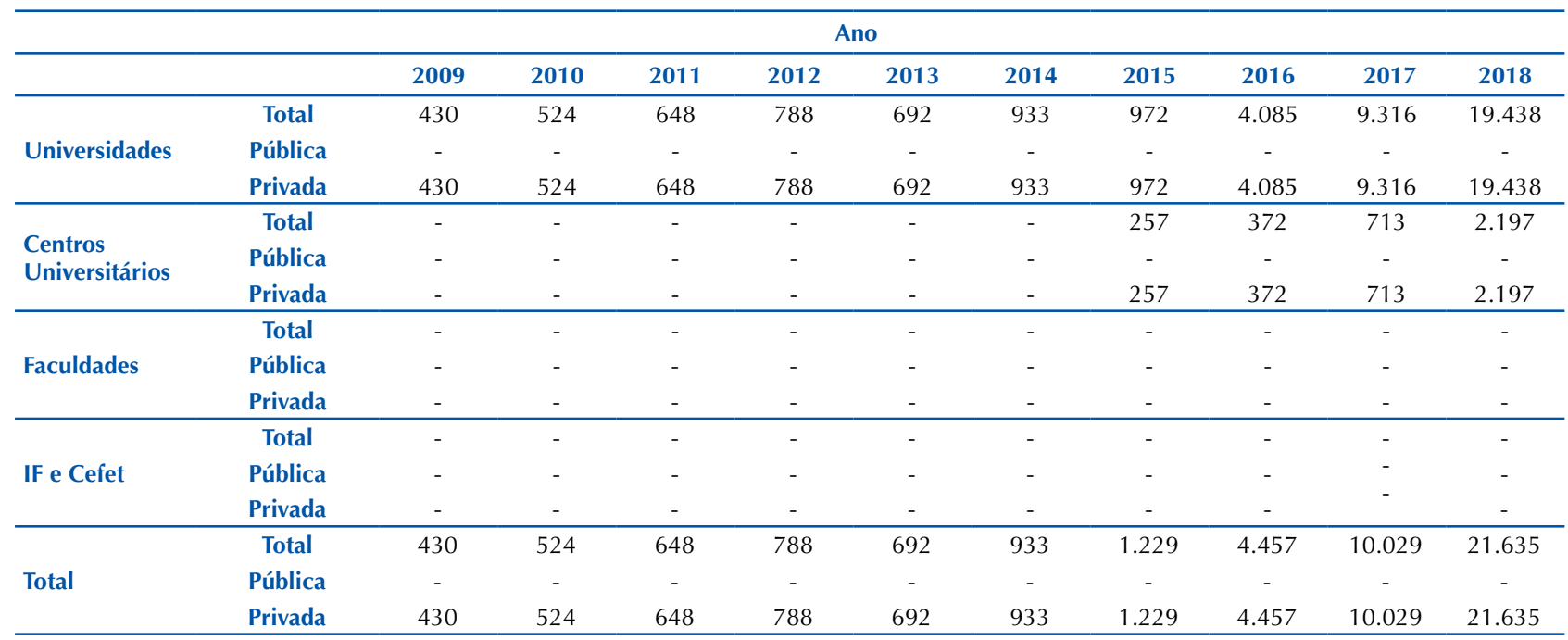

Fonte: INEP/MEC.

Como pode ser observado na Tabela 2, desde 2016 há aumento acentuado do número de matrículas nos cursos EAD em Enfermagem, de aproximadamente 19 vezes, entre 2015 e 2018. Entretanto, o mesmo não ocorre com o número de concluintes.

No que se refere à relação entre as vagas ofertadas, os candidatos inscritos e o ingresso nos cursos EAD em Enfermagem, o crescimento não é linear e ascendente; tampouco há o preenchimento total das vagas. Por mais que tenha havido aumento na relação candidato/vaga (de 0,3 em 2009 para 1,136 em 2018) e na relação ingresso/vaga (de 0,09 em 2009 para 0,336 em 2018), indicando alguma demanda por essa modalidade de curso, a quantidade de vagas preenchidas nesses anos corresponde a 9,05\% e 33,6\%, respectivamente ${ }^{(17)}$. Tal situação reforça o argumento de que a oferta de vagas não significa necessariamente ampliação do acesso. Revela, entretanto, que, nos anos recentes, houve grande ampliação da oferta de vagas e ligeiro crescimento da demanda (número de candidatos inscritos).

Entre os anos de 2009 e 2018, foram ofertadas 26.401 .654 vagas, realizadas 12.317 .848 matrículas e 1.944 .012 alunos concluíram o curso de graduação por EAD no Brasil. Ou seja, $46,66 \%$ das vagas foram ocupadas, $15,78 \%$ dos matriculados concluíram o curso e apenas $7,36 \%$ das vagas ofertadas tiveram alunos concluintes ${ }^{(17)}$.

No que se refere especificamente à Enfermagem, nesse período, foram ofertadas 288.281 novas vagas em EAD, houve 29.759 matrículas e 763 concluintes. Ou seja, apenas $10,32 \%$ das vagas foram ocupadas, somente $2,56 \%$ dos matriculados concluíram o curso e os concluintes, nesse período, corresponderam a apenas $0,264 \%$ das vagas oferecidas ${ }^{(17)}$.

No ensino presencial, nesse mesmo período, foram ofertadas 1.307.839 vagas, houve 2.534.404 matrículas e 387.608 
concluintes, ou seja, $57,0 \%$ das vagas foram preenchidas e $46,7 \%$ dos matriculados concluíram o curso ${ }^{(17)}$.

Ainda que esses resultados devam ser ponderados, considerando o tempo de conclusão do curso, as transferências entre cursos e a evasão, reiteram os argumentos relativos à falácia em torno da democratização da educação promovida pelo EAD, bem como revelam os interesses mercadológicos na oferta dessa modalidade de ensino.

\section{DISCUSSÃO}

A ampliação do acesso à Educação Superior no Brasil ocorreu por meio de expansão da oferta de cursos, crescimento das matrículas no setor privado e racionalização de recursos nas instituições públicas de ensino superior ${ }^{(15)}$. Trata-se de um crescimento marcado pela preponderância do privado sobre o público, bem como da mercadorização e mercantilização da educação. A expansão tem se caracterizado pelo imediatismo e crescimento numérico, em especial das instituições privadas voltadas para absorver um grande número de estudantes. Tais instituições, em sua maioria, caracterizam-se por baixa produção de conhecimento, ênfase na formação de carreiras que exigem pouco investimento e, por isso, atraem um número maior de estudantes com problemas relacionados à qualidade da formação ${ }^{(18)}$.

A característica dual, setor público e setor privado, do ensino superior brasileiro está garantida desde 1891, o que permitiu que, ao longo de mais de um século, o Estado brasileiro desenvolvesse uma série de legislações para assegurar a unidade do sistema nacional, atuando ora como agente regulador ora como modulador da oferta. A partir da década de 1990, com a Lei de Diretrizes e Bases para a Educação (LDB), houve a flexibilização do ensino superior público e um novo aparato legal permitiu o ajuste do sistema de ensino às regras do mercado. Assim, a flexibilização e a heterogeneidade do sistema marcam as diferenças entre o privado e público, mas também se reproduzem em cada um deles ${ }^{(19)}$.

Com a abertura ao mercado, as instituições privadas de ensino superior passaram a ser negociadas por meio de processos de aquisição e fusão, com destaque para a abertura de capital na bolsa de valores e possibilidades de articulação com corporações internacionais de educação. Esse movimento produz impactos em vários aspectos, entre eles, a forma de contratação docente, a inclusão e a ampliação do EAD e, por consequência, afeta a qualidade do ensino oferecido nessas instituições ${ }^{(19)}$.

Portanto, o ensino superior brasileiro constitui um fenômeno histórico, complexo e contraditório que não é neutro e tampouco isolado da dinâmica da sociedade, das necessidades sociais, da reestruturação produtiva, dos movimentos neoconservadores e dos interesses envolvidos na produção e na valorização do capital. Ao mesmo tempo em que possibilita o acesso de grande parcela da população historicamente excluída desse nível de ensino, é prioritariamente de natureza privatizante e com qualidade social questionável.

A essa complexidade acrescenta-se o cenário atual de fragilização dos recursos para o ensino superior público, especialmente com a aprovação da Proposta de Emenda à Constituição $n^{\circ} 241$, a PEC 241, que prevê, entre outros aspectos, o congelamento dos gastos nas área de educação e saúde por 20 anos, o que coloca em risco a sustentabilidade e a garantia da qualidade no ensino superior público ${ }^{(20)}$. Os impactos nas IES federais relacionam-se à possibilidade de não cumprimento das metas estabelecidas no PNE (20142024), pois isso implicaria dobrar os recursos para aumentar o número de matrículas previsto, cenário pouco provável no contexto da $\mathrm{PEC}^{(20)}$.

$\mathrm{O}$ ensino superior em Enfermagem, como parte do sistema, acompanha esse processo. Houve expansão no número de cursos de graduação presenciais em Enfermagem de IES públicas e privadas, com predomínio de cursos em centros universitários e faculdades privados, o que significa que está ocorrendo no Brasil um processo de formação em Enfermagem centrado no ensino privado, em que os interesses do mercado sobrepõem-se aos interesses sociais do coletivo e do direito à educação e à saúde.

$\mathrm{Na}$ primeira década das Diretrizes Curriculares Nacionais (2001-2011), o aumento do número de cursos da rede pública foi pequeno, ao contrário da rede privada, em que o aumento foi vertiginoso. $\mathrm{O}$ número de inscritos no processo seletivo desses cursos foi consideravelmente maior que o número de vagas ofertadas, com cerca de cinco candidatos por vaga. $\mathrm{O}$ número de concluintes no setor público manteve-se quase inalterado em razão da estagnação do número de cursos e vagas, bem como da evasão. Nesse período, já havia 19.680 vagas em cursos de graduação a distância ${ }^{(16)}$.

Apesar do número expressivo da força de trabalho de Enfermagem e da ampliação do número de cursos, há concentração e disponibilidade desiguais de profissionais de Enfermagem por habitante, insuficiente em algumas regiões do País, desde 2012. O eixo Sul-Sudeste concentrava 71,2\% dos cursos de Graduação em Enfermagem do país. Isso porque a maioria dos cursos situa-se em áreas com maior densidade populacional e concentração de recursos educacionais, o que contribui para aprofundar as desigualdades regionais ${ }^{(21)}$.

Evidencia-se assim que o movimento de expansão dos cursos de graduação em Enfermagem não veio acompanhado de estudos sobre as necessidades e as demandas específicas de cada região. Ao contrário, esse movimento reflete a lógica de mercantilização da educação, cedendo às pressões de grupos interessados em adquirir e acumular capital, sem considerar as necessidades e as demandas da saúde e da educação ${ }^{(15)}$. "Não basta crescer a qualquer custo, é importante crescer desde que seja garantido o critério de qualidade e pertinência da formação. É necessário expandir, mas com garantia de padrões de qualidade compatíveis com o mundo contemporâneo e com vinculação mais estreita entre o mundo do trabalho e o mundo da formação"(22).

Se, por um lado, a expansão da educação superior em Enfermagem sinaliza uma possível democratização do acesso, por outro, "há que se indagar sobre a oferta de postos de trabalho para o enfermeiro, bem como a relação entre a qualidade e a quantidade dos profissionais requeridos para a consolidação do Sistema Único de Saúde”(21). Ao mesmo tempo em que é necessário ampliar o número de enfermeiros no País, é preciso que sejam formados em cursos com qualidade social, comprometidos com a implementação do 
Sistema Único de Saúde (SUS), como forma de enfrentar desigualdades e iniquidades sociais ${ }^{(15)}$.

Dentro desse movimento de expansão da Educação Superior em Enfermagem, merece destaque a expressiva ampliação de vagas e matrículas na modalidade EAD. Diferentemente do ensino presencial, em que há oferta de cursos em IES públicas e privadas, no EAD em Enfermagem, a oferta ocorre exclusivamente em instituições privadas, predominantemente por meio da ampliação de vagas, aprofundando os desafios já citados. Após a nova regulamentação do EAD no Brasil, em 2017, que flexibilizou a oferta de cursos, observa-se tendência ainda maior de expansão dessa modalidade na Enfermagem, conforme mostra o Censo da Educação Superior de 2018.

Em termos de orientação nacional, tanto os cursos presenciais quanto os a distância, seguem as Diretrizes Curriculares Nacionais dos Cursos de Graduação em Enfermagem. Desse modo, não há diferenças explícitas no perfil do egresso, objetivos do curso, competências, habilidades e organização curricular nos projetos pedagógicos. Contudo, entidades representativas da saúde ${ }^{(23)}$ e da Enfermagem ${ }^{(24)}$, bem como pesquisas nacionais e internacionais ${ }^{(25-28)}$, têm problematizado as potencialidades e os limites da implementação de cursos EADs na saúde e na Enfermagem.

Há preocupação quanto à concretização das competências e das habilidades necessárias ao trabalho do enfermeiro ${ }^{(25,28)}$, à qualificação incipiente de professores e alunos para o uso crítico do espaço educativo digital, à substituição do professor pelo tutor, ao contato restrito do aluno com a realidade dos serviços de saúde ${ }^{(28)}$, à interação escassa com profissionais e usuários desses serviços e à experiência social restrita, à sobrecarga do trabalho docente ${ }^{(27)} \mathrm{e}$ à disponibilidade de infraestrutura adequada e acessível ${ }^{(26)}$.

Essas preocupações partem da premissa de que os elementos definidores da formação e do trabalho em saúde dependem das relações sociais concretas que ocorrem nos espaços de produção de serviços de saúde e construção da própria vida, portanto, na presencialidade. Além disso, reconhecem que a formação a distância não pode intensificar a precarização do trabalho docente, ser produtora de exclusão social e acentuar o discurso da meritocracia.

O uso associado e complementar de tecnologias da informação e comunicação na formação presencial possibilita a diversificação e a ampliação das práticas pedagógicas ${ }^{(25,28)}$, porém é necessário cautela na hibridização ${ }^{(25)}$, já que há lacunas e incertezas sobre o impacto dos recursos tecnológicos na formação em saúde/enfermagem ${ }^{(28)}$. $\mathrm{O}$ uso de tais recursos precisa ter coerência com os objetivos do curso, a finalidade da formação e o perfil desejado para o egresso. Deve ademais garantir o acesso igualitário e qualificado a todos os envolvidos.

Diante da expansão de cursos EAD no Brasil, desde 2016, o Conselho Nacional de Saúde (CNS) posicionou-se contrário a todo e qualquer curso de graduação em saúde na modalidade EAD. Ao assumir o protagonismo nesse enfrentamento, o CNS reconheceu "os prejuízos que tais cursos podem oferecer à qualidade da formação de seus profissionais, bem como os riscos que estes profissionais possam causar à sociedade, [de] imediato, a médio e a longo prazos, refletindo uma formação inadequada"(23).

Essa preocupação é reiterada nos Seminários Nacionais de Diretrizes para Educação em Enfermagem (Senaden), de modo especial nas quatro últimas edições, em que a problemática foi tema de vários debates e encaminhamentos contrários à formação de enfermeiros na modalidade de EAD. Tal posicionamento da categoria está presente nas novas Diretrizes Curriculares Nacionais, em tramitação no Ministério da Educação, que definem a exclusividade da formação do enfermeiro na modalidade presencial.

A Associação Brasileira de Enfermagem (ABEN), juntamente com outras 58 entidades, assinou a "Nota Pública Contra a Graduação a Distância na Área da Saúde: formação com qualidade na área da saúde somente na modalidade presencial!". A ABEN reconhece como imprescindível para a formação em saúde a inserção dos estudantes na rede de serviços de saúde do SUS e nos equipamentos sociais onde vivem e trabalham os usuários desse sistema. Defende uma formação em que haja a compreensão crítica das necessidades sociais, mediante a articulação permanente entre teoria e prática ${ }^{(24)}$.

A Nota acrescenta ainda que a maioria dos cursos de graduação presenciais da área não preenche as vagas ofertadas, demonstrando a impropriedade e a falta de necessidade social do EAD na saúde e na Enfermagem. Além disso, afirma que a análise dos cursos de graduação EAD na saúde já revela um quadro incompatível com o adequado exercício profissional ${ }^{(29)}$. Tal cenário é agravado pelo Decreto no 9.057 de 25 de maio de 2017, que permite o credenciamento de IES exclusivamente para oferta de cursos de graduação na modalidade a distância, sem prever uma distinção para os cursos da área da saúde ${ }^{(10)}$.

Diante do exposto, é necessário fomentar a compreensão crítica acerca dos interesses envolvidos com a expansão do EAD, em particular nos cursos da área da saúde. Não podem ser aceitos de forma acrítica os argumentos de inovação tecnológica, flexibilidade, quebra de barreiras espaciais e temporais, incentivo à criatividade, agilidade no acesso a várias fontes de informação e autonomia do discente. $\mathrm{O}$ EAD é mais uma estratégia para a ampliação do lucro, sob a dominância cada vez maior do capital financeiro ${ }^{(29)}$.

Este estudo representa apenas uma aproximação com a realidade da expansão dos cursos de graduação em Enfermagem, nas modalidades presencial e EAD. Faz-se necessário o aprofundamento das especificidades loco-regionais e das percepções dos sujeitos envolvidos no processo de formação em saúde e Enfermagem.

\section{CONCLUSÃO}

Em que pesem as especificidades do trabalho em saúde e Enfermagem, a expansão do ensino superior em Enfermagem está articulada ao movimento mais geral da Educação Superior brasileira. Faz parte de um movimento histórico-social de mercantilização e mercadorização da educação, agravado com a ampliação do EAD.

Defender a democratização do acesso ao ensino superior pressupõe a defesa da educação como bem público e 
direito social que contribui para o desvelamento da realidade, bem como para a transformação das injustiças e iniquidades sociais. Requer, portanto, o enfrentamento da lógica perversa, desumanizadora e individualista do capital, que reduz a educação a mercadoria.
É necessário que as políticas de expansão dos cursos da área da saúde e Enfermagem estejam ancoradas no pleno direito à educação pública, nas necessidades sociais regionais e no trabalho em saúde, possibilitando acesso, permanência e conclusão com equidade e justiça social.

\section{RESUMO}

Objetivo: Analisar a expansão dos cursos de graduação em Enfermagem, em particular, na modalidade de Ensino a Distância. Método: Estudo exploratório, descritivo, analítico e documental que utilizou como fonte de dados secundários as Sinopses Estatísticas da Educação Superior - Graduação, do Instituto Nacional de Estudos e Pesquisas Educacionais Anísio Teixeira do Ministério da Educação - entre os anos de 2009 e 2018. Resultados: Observou-se crescimento do número de cursos e de novas vagas na modalidade a distância. Entretanto, apenas 8,89\% dessas vagas ofertadas foram ocupadas, 3,39\% dos matriculados concluíram o curso e 0,30\% das vagas ofertadas tiveram alunos concluintes. Conclusão: A expansão dos cursos de graduação em Enfermagem está articulada ao movimento geral da Educação Superior. Esse cenário revela os interesses do capital na educação, requerendo a construção coletiva de estratégias para a garantia do direito à educação pública, gratuita e com qualidade social.

\section{DESCRITORES}

Educação Superior; Educação a Distância; Enfermagem.

\section{RESUMEN}

Objetivo: Analizar la expansión de cursos de grado en Enfermería, particularmente en modalidad de enseñanza a distancia. Método: Estudio exploratorio, descriptivo, analítico y documental, utilizando como fuente de datos secundarios las Sinopsis Estadísticas de Educación Superior - Graduación del Instituto Nacional de Estudios y Encuestas Educativas Anísio Teixeira, del Ministerio de Educación, entre 2009 y 2018. Resultados: Se observó crecimiento cuantitativo de cursos y de nuevas vacantes en modalidad a distancia. Sin embargo, solo el 8,89\% de las vacantes ofrecidas fueron ocupadas, 3,39\% de los matriculados concluyeron el curso y $0,30 \%$ de las vacantes ofrecidas correspondieron a alumnos egresados. Conclusión: La expansión de cursos de grado en Enfermería está articulada al movimiento general de la Educación Superior. Este escenario revela los intereses del capital en la educación, requiriendo de la construcción colectiva de estrategias que garanticen el derecho a la educación pública, gratuita y con calidad social.

\section{DESCRIPTORES}

Educación Superior; Educación a Distancia; Enfermería.

\section{REFERÊNCIAS}

1. Chesnais F. A finança mundializada: Raízes sociais e políticas, configurações e consequências. São Paulo: Boitempo; 2005. O capital portador de juros: acumulação, internacionalização, efeitos econômicos e políticos; p. 35-68.

2. Teston LM, Mendes A, Carnut L, Junqueira V. Avaliação no SUS: uma crítica à ideologia do produtivismo no capitalismo contemporâneo. Saúde Debate. 2018; 42(n esp. 3):226-239. https://doi.org/10.1590/0103-11042018s317

3. Mendes A. A saúde no capitalismo financeirizado em crise: o financiamento do SUS [Internet]. 2017 [cited 2018 Dec 3] (Futuros do Brasil, ideias para ação). Available from: http://www.cee.fiocruz.br/sites/default/files/Artigo_Aquilas_Mendes_.pdf

4. Chauí M. A ideologia da competência. 3rd ed. São Paulo: Fundação Perseu Abramo/Autêntica; 2014. (Escritos de Marilena Chauí).

5. Boschetti I. [Tensions and possibilities of Social Welfare policy in the context of the crisis of capital]. Argum. 2016;8(2):16-29. Portuguese. https://doi.org/10.18315/argumentum.v8i2.12800

6. Mancebo D, Bittar M, Chaves VL. Educação superior: expansão e reformas educativas, organizadoras. Maringá: Eduem; 2012. Educação superior, expansão e reformas educativas; p. 13-20.

7. Mancebo D, Silva Júnior JR, Schugurensky D. Silva Junior Jr, Schugurensky D. [Brazilian higher education in face of capital globalization]. Educ Rev. 2015;32(4):205-25. Portuguese. https://doi.org/10.1590/0102-4698162033.

8. Mancebo D, Vale AA, Martins TB. [Expansion of higher education policy in Brazil: 1995-2010]. Rev Bras Educ. 2015;20(60):31-50. Portuguese. https://doi.org/10.1590/S1413-24782015206003

9. Moore JL, Dickson-Deane C, Galyen K. e-Learning, online learning, and distance learning environments: are they the same? Internet High Educ. 2011;14(2):129-35. https://doi.org/10.1016/j.iheduc.2010.10.001.

10. Brasil. Decreto $n^{\circ}$ 9.057, de 25 de maio de 2017. Dispõe sobre a regulamentação do art. 80 da Lei no 9.394 , de 20 de dezembro de 1996 , que estabelece as diretrizes e bases da educação nacional. Diário Oficial União, Brasília, DF. 2017 May 26;Section 1.

11. Brasil. Lei $n^{\circ}$ 9.394, de 20 de dezembro de 1996. Estabelece as diretrizes e bases da educação nacional. Diário Oficial União, Brasília, DF. 1996 Dec 20;Section 1.

12. Brasil. Ministério da Educação. Atualizada legislação que regulamenta Educação a Distância no país [Internet]. 2017 May 26 [cied 2019 Sep 30]. Available from: http://portal.mec.gov.br/ultimas-noticias/212-educacao-superior-1690610854/49321-mec-atualiza-legislacaoque-regulamenta-educacao-a-distancia-no-pais

13. Erdmann AL, Fernandes JD, Teixeira GA. [Overview of nursing education in Brazil: graduation and post graduation]. Enferm Foco. 2011;2(supl):89-93. Portuguese. https://doi.org/10.21675/2357-707X.2011.v2.nSUP.91

14. Egry EY, Fonseca RM. Acerca da qualidade nas pesquisas qualitativas em Enfermagem. In: Souza FN, Souza DN, Costa AP, organizadores. Investigação qualitattiva. inovação, dilemas e desafios. 2nd ed. Aveiro: Ludomedia; 2015. p. 75-102.

15. Fernandes JD, Teixeira GA, Silva MG, Florêncio RM, Silva RM, Rosa DO. Expansion of higher education in Brazil: increase in the number of Undergraduate Nursing courses. Rev Latino-Am Enfermagem. 2013;21(3):1-8. https://doi.org/10.1590/S0104-11692013000300004 
16. Teixeira E, Fernandes JD, Andrade AC, Silva KL, Rocha ME, Lima RJ. [Overview of nursing graduation courses in Brazil in the National Curriculum Guidelines decade]. Rev Bras Enferm. 2013; 66(esp.):102-10. Portuguese. https://doi.org/10.1590/S0034-71672013000700014

17. Instituto Nacional de Estudos e Pesquisas Educacionais Anísio Teixeira. Sinopses estatísticas da educação superior [Internet]. Brasília, DF: Instituto Nacional de Estudos e Pesquisas Educacionais Anísio Teixeira; 2019 [cited 2019 Sep 30]. Available from: http://inep.gov.br/ sinopses-estatisticas-da-educacao-superior

18. Mancebo D, coord. Políticas de expansão da educação superior no Brasil pós-LDB: projeto de pesquisa [Internet]. Rede Universitas/Br; 2009 [cited 2018 Dec 8]. Available from: http://www.anped11.uerj.br/projetouniversitas.pdf

19. Sampaio H. [Diversity and differentiation in brazilian higher education: concepts for discussion]. Rev Bras Cienc Soc. 2014;29(84):43-55. Portuguese. https://doi.org/10.1590/S0102-69092014000100003

20. Amaral NC. [PEC 241/55: PNE's “death" (2014-2024) and the power of diminishing educational resources]. RBPAE. 2016;32(3):653-673. Portuguese. https://doi.org/10.21573/vol32n32016. 70262

21. Silva KL, Sena RR, Tavares TS, Wan der Maas L. [Expansion of Undergraduate Nursing and the labor market: reproducing inequalities?] Rev Bras Enferm. 2012;65(3):406-13. Portuguese. https://doi.org/10.1590/S0034-71672012000300003

22. Fernandes JD. Expansion of courses/places for Nursing Graduation and the quality of nurse's education process. Rev Bras Enferm. 2012;65(3):395-6. https://doi.org/10.1590/S0080-623420130000500028

23. Brasil. Ministério da Saúde. Conselho Nacional de Saúde. Resolução no 515, de 7 de outubro de 2016. Diário Oficial União, Brasília, DF. 2016 Nov 11;Section 1:61.

24. Sindicato dos Enfermeiros do Estado de São Paulo. Nota Pública: Contra a Graduação a Distância na Área da Saúde - Formação com qualidade na área da Saúde somente na modalidade presencial! [Internet] 2017 Nov 27 [cited 2018 Dec 8]. Available from: http://seesp. com.br/noticias/nota-publica-contra-graduacao-distancia-na-area-da-saude-formacao-com-qualidade-na-area-da-saude-somente-namodalidade-presencial/

25. McDonald EW, Boulton JL, Davis JL. E-learning and nursing assessment skills and knowledge: an integrative review. Nurse Educ Today. 2018;66:166-74. https://doi.org/10.1016/j.nedt.2018.03.011

26. Njenga JK, Fourie LC. The myths about e-learning in higher education. Br J Educ Technol. 2010;41(2):199-212. https://doi.org/10.1111/ j.1467-8535.2008.00910.x

27. Button D, Harrington A, Belan I. E-learning \& information communication technology (ICT) in nursing education: a review of the literature. Nurse Educ Today. 2014;34(10):1311-23. https://doi.org/10.1016/j.nedt.2013.05.002

28. Sanes MD, Neves FB, Pereira LE, Ramos FR, Brehmer LC, Vargas MA, et al. No to distance education! Production of meaning of discourses of nursing representative entities. Rev Bras Enferm. 2020;73(5):e20190465. https://doi.org/10.1590/0034-7167-2019-0465

29. Pimenta AM. [The distance education as a renewal of the Brazilian educational market of the higher level]. Rev Inter Educ Sup. 2017;3(2):308-21. Portuguese. https://doi.org/10.22348/riesup.v3i2.7762

Coordenadoria de Aprimoramento de Pessoal de Nível Superior (Capes). 